\title{
Insight toward the Electrochemical properties of Sulfonated Poly(2,6-dimethyl- 1,4-phenylene oxide) via Impregnating Functionalized Boron Nitride: Alternate Composite Polymer Electrolyte for Direct Methanol Fuel Cell
}

\author{
Vikrant Yadav $^{\text {a,b }}$, Nagaraju Niluroutu ${ }^{\text {c }}$, Santoshkumar D. Bhat ${ }^{*}$,c, Vaibhav Kulshrestha**,a,b \\ ${ }^{a}$ CSIR-Central Salt \& Marine Chemicals Research Institute, Gijubhai Badheka Marg, Bhavnagar \\ 364 002, Gujarat, India \\ ${ }^{\mathrm{b}}$ Academy of Scientific \& Innovative Research (AcSIR), Ghaziabad 201002, India \\ ${ }^{\mathrm{c}}$ CSIR-Central Electrochemical Research Institute-Madras Unit, Chennai, India \\ E-mail: *sdbhatcecri@gmail.com;
}

\section{Section S1. Physico-chemical characterization}

The vacuum dried membrane samples of $2 \times 2 \mathrm{~cm}$ were initially weighed $\left(\mathrm{W}_{\text {dry }}\right)$ and then were equilibrated with de-ionized water in a sorption chamber for $24 \mathrm{~h}$ at $30^{\circ} \mathrm{C}$. The equilibrated membranes were carefully surface sorbed to remove excess water followed by weighing ( $\mathrm{w}_{\text {wet }}$ ). Water sorption for the prepared membranes is calculated using following relation:

Water Sorption $=\frac{W_{w e t}-W_{d r y}}{W_{d r y}} \times 100 \%$

Where $\mathrm{W}_{\text {wet }}$ is the weight of wet membrane sample and $\mathrm{W}_{\text {dry }}$ is the weight of the dry membrane sample. Triplicate measurements were carried out for all the samples and the error is within \pm 2 $\%$.

Ion exchange capacity (IEC) for synthesized membranes was measured by acid-base titration. The Dried membrane samples were immersed in $1 \mathrm{M} \mathrm{HCl}$ solution at $30^{\circ} \mathrm{C}$ for $24 \mathrm{~h}$ followed by repeated washing with de-ionized water for complete removal of residual acid from membrane surface. Further, membrane samples were equilibrated with $1 \mathrm{M} \mathrm{NaCl}$ solution for $24 \mathrm{~h}$ under similar 
conditions to replace $\mathrm{H}^{+}$with $\mathrm{Na}^{+}$ion. Solution with $\mathrm{H}^{+}$ions was titrated with $0.01 \mathrm{~N} \mathrm{NaOH}$ solution wherein phenolphthalein is used as an indicator. The IEC for membranes (meq./g) is calculated using the following equation:

$\mathrm{IEC}=\frac{V_{\mathrm{NaOH}} \times N_{\mathrm{NaOH}}}{W_{d r y}}(\mathrm{meq} . / \mathrm{g})$

Where $\mathrm{V}_{\mathrm{NaOH}}$ is the volume of $\mathrm{NaOH}$ consumed during titration, $\mathrm{N}_{\mathrm{NaOH}}$ is the normality of $\mathrm{NaOH}$ and $\mathrm{W}_{\text {dry }}$ is the dry weight of the membrane sample.

Data for ion exchange capacity and water sorption were recorded with three different membrane samples and average values for IEC and water sorption are presented in this study.

The number of water molecules per ionic site $\left(\mathrm{H}_{2} \mathrm{O} / \mathrm{SO}_{3}{ }^{-}\right)$was calculated using following equation:

$\lambda=\frac{W U \times 10}{18.01 \times I E C}$

The swelling was determined by the difference between wet and dry thickness of a membrane sample and was calculated based on the following equation:

$\mathrm{SR}=\frac{T_{w e t}-T_{d r y}}{T_{d r y}} \times 100$

Where $\mathrm{T}_{\text {wet }}$ and $\mathrm{T}_{\mathrm{dry}}$ are the thickness of wet and dry membrane sample, respectively.

\section{Section S2. Proton Conductivity}

Proton conductivity for composite membranes under $100 \%$ relative humidity was measured using four-probe AC impedance spectroscopy technique. Test sample with required size and thickness was clamped in BekkTech LLC conductivity cell with inbuilt four platinum probes. Conductivity cell was placed in ESPEC humidity and temperature chamber (SH-242) and connected with a 
single channel potentiostat (BioLogic, SP-150). Each of the membrane samples was scanned over a frequency range of $1 \mathrm{~Hz}$ to $1 \mathrm{MHz}$ from 30 to $70^{\circ} \mathrm{C}$. The membrane area resistance was obtained by Nyquist plot, through high-frequency intercept with real axis and proton conductivity was calculated using the following relation:

Proton conductivity $(\sigma)=\frac{d}{R \times T \times W}(\mathrm{~S} / \mathrm{cm})$

Where $R$ is the test sample resistance obtained from the real axis of the impedance spectra, $d$ is the distance between probes in conductivity cell $(0.425 \mathrm{~cm}), T$ and, $W$ are the thickness and width of test sample, respectively.

The activation energy for proton conduction was measured by using linear Arrhenius relation between $\ln$ of proton conductivity and temperature (1000/T). Following equation is used to calculate activation energy for proton conduction:

$E_{a}=-b \times R$

Where $E_{a}$ is the activation energy $\left(\mathrm{kJ} \mathrm{mol}^{-1}\right)$ for proton conduction, $\mathrm{b}$ is the slope of linear regression of Arrhenius plot (ln $\sigma$ vs. 1000/T) and $\mathrm{R}$ is the gas constant $\left(8.314 \mathrm{~J} \mathrm{~K}^{-1} \mathrm{~mol}^{-1}\right)$. 

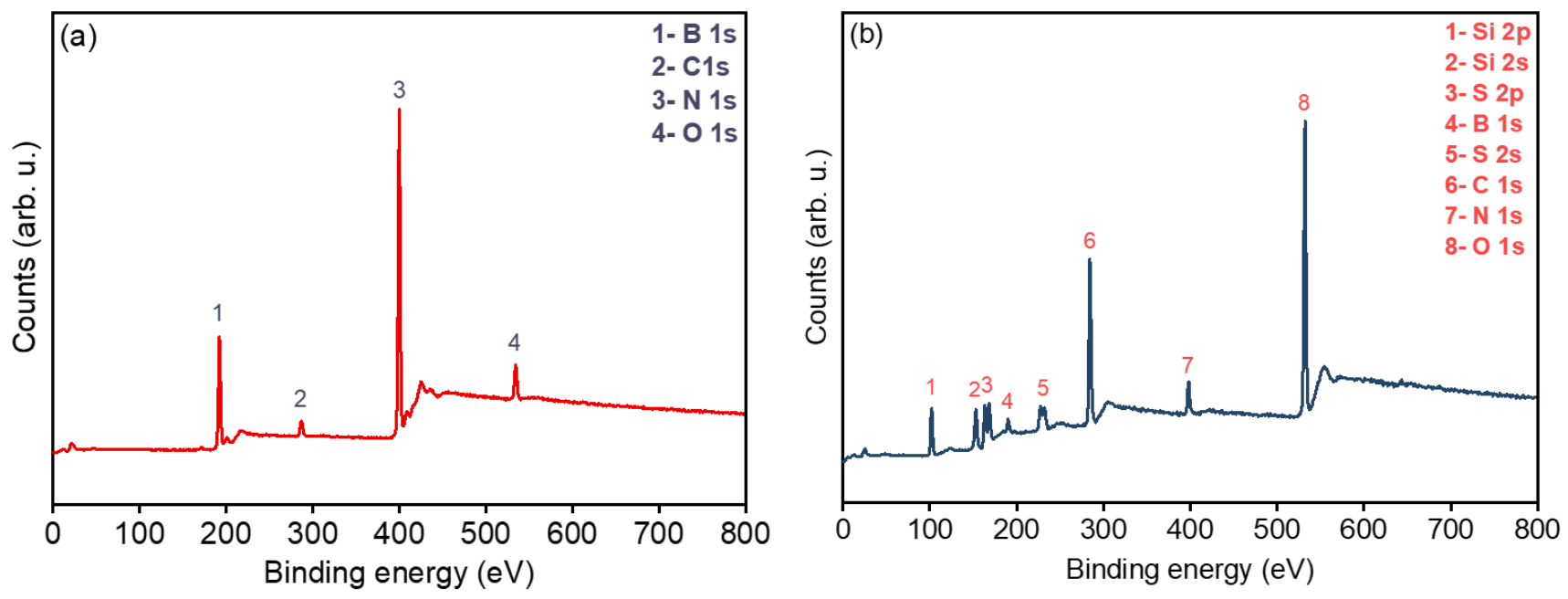

Fig. S1 XPS survey for boron nitride (a), and sulfonated boron nitride (b).

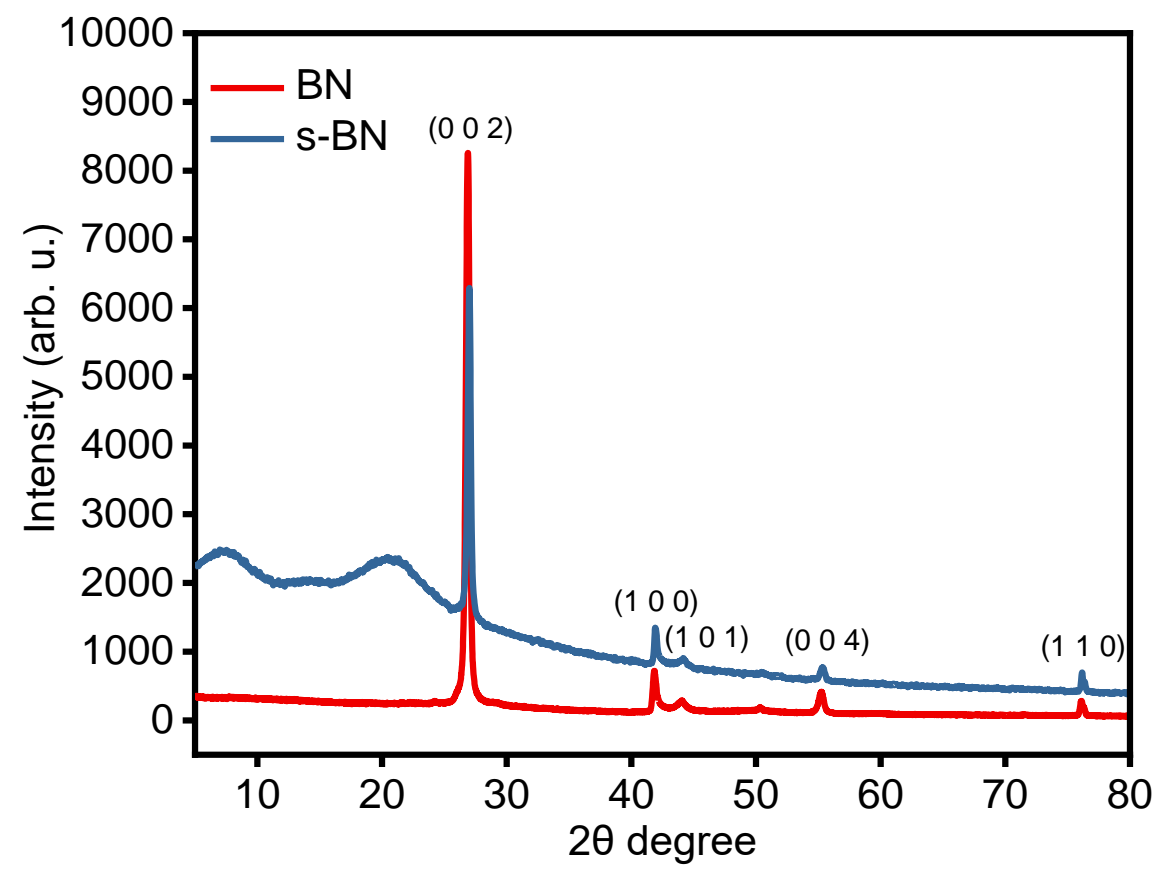

Fig. S2 X-ray diffraction pattern for boron nitride (BN) and sulfonated boron nitride (s-BN). 


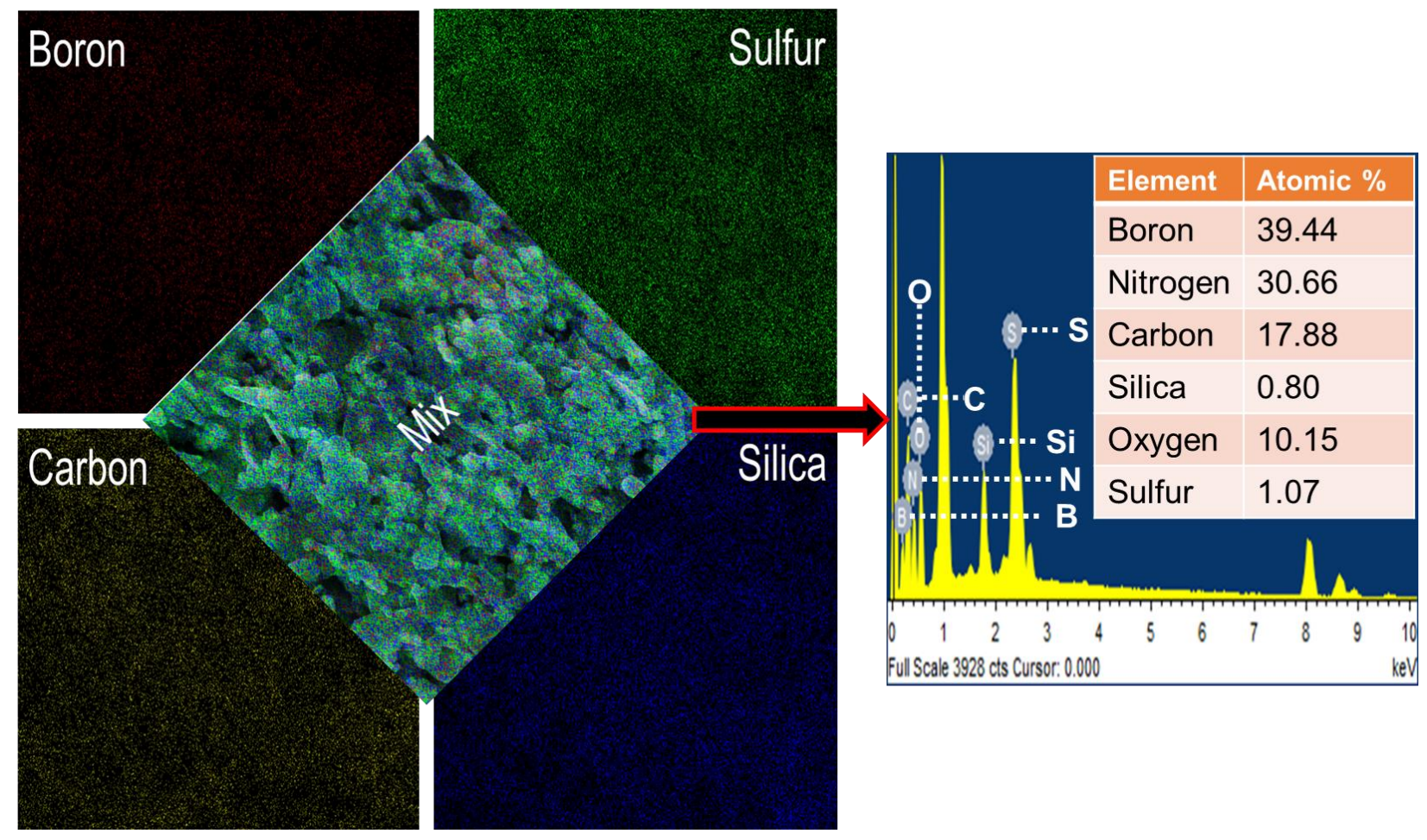

Fig. S3 elemental mapping and EDX analysis of sulfonated boron nitride

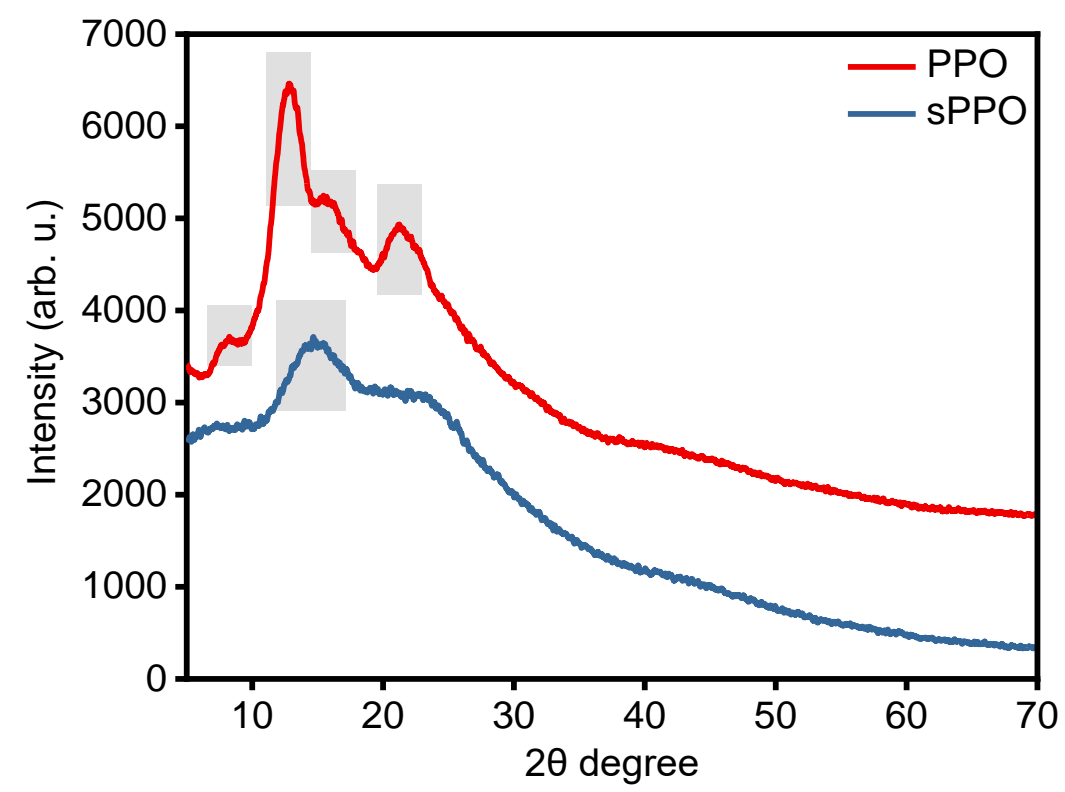

Fig. S4 X-ray diffraction pattern for $\operatorname{poly}(2$, 6-dimethyl-1, 4-phenylene oxide) (PPO) and sulfonated poly(2, 6-dimethyl-1, 4-phenylene oxide) (sPPO). 


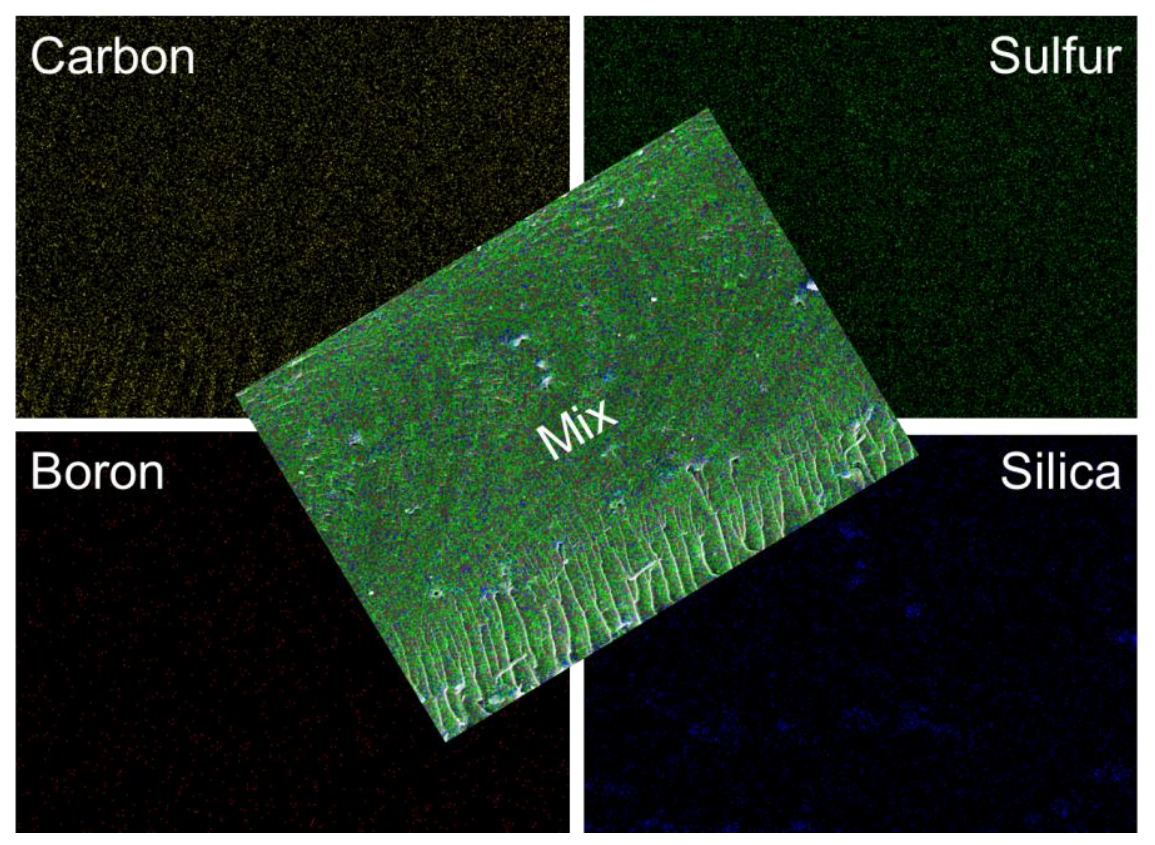

Fig. S5 Elemental mapping of SP-5 (5 wt. \% s-BN) composite membrane to validate uniform distribution of s-BN across sPPO matrix.
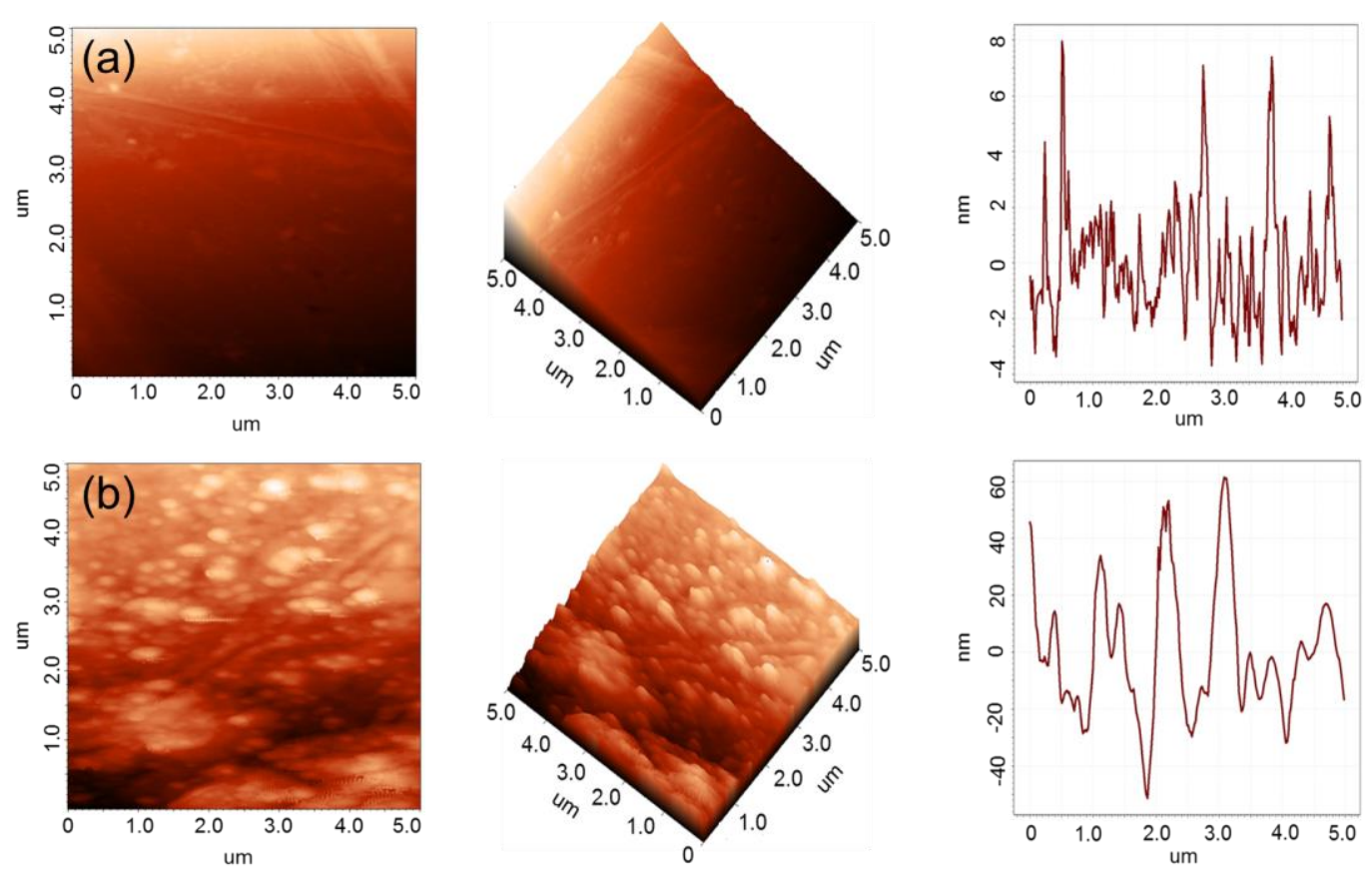

Fig. S6 Surface topology for (a) pristine sPPO membrane and (b) SP-5 (5 wt. \% s-BN) composite membrane along with their roughness profiles. 


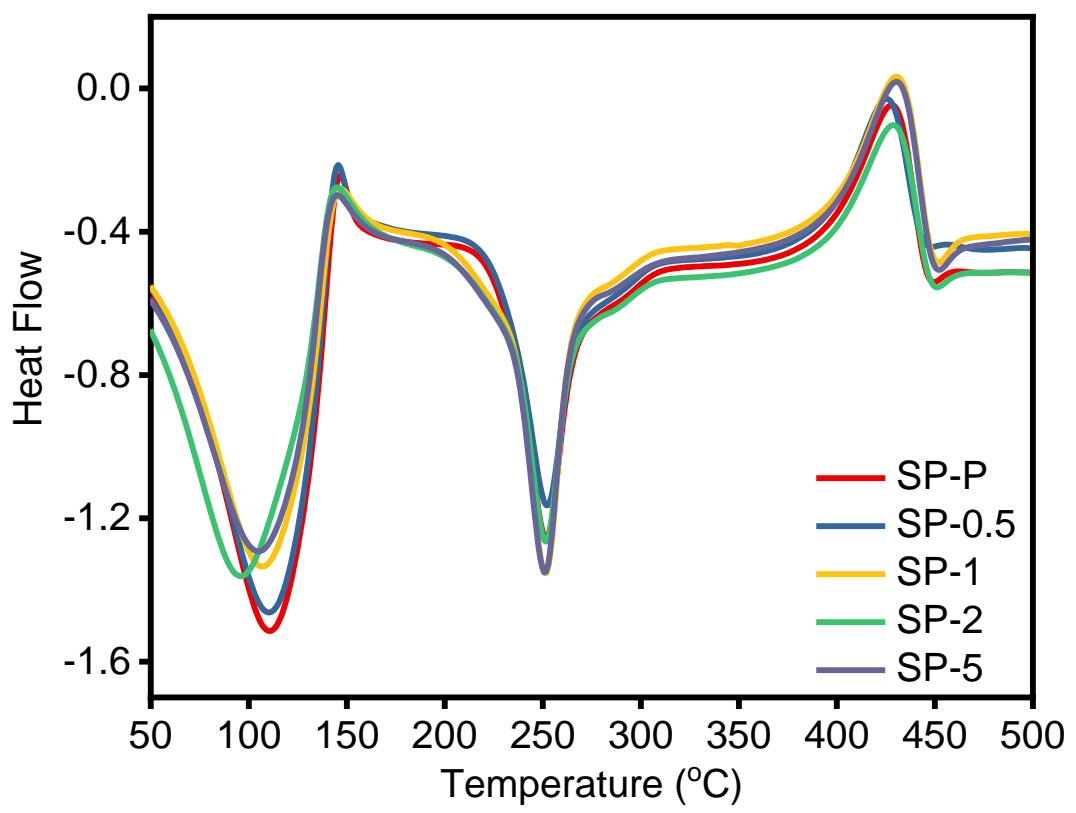

Fig. S7 Differential scanning calorimetry spectra for pristine sPPO and s-BN/sPPO composite membranes.

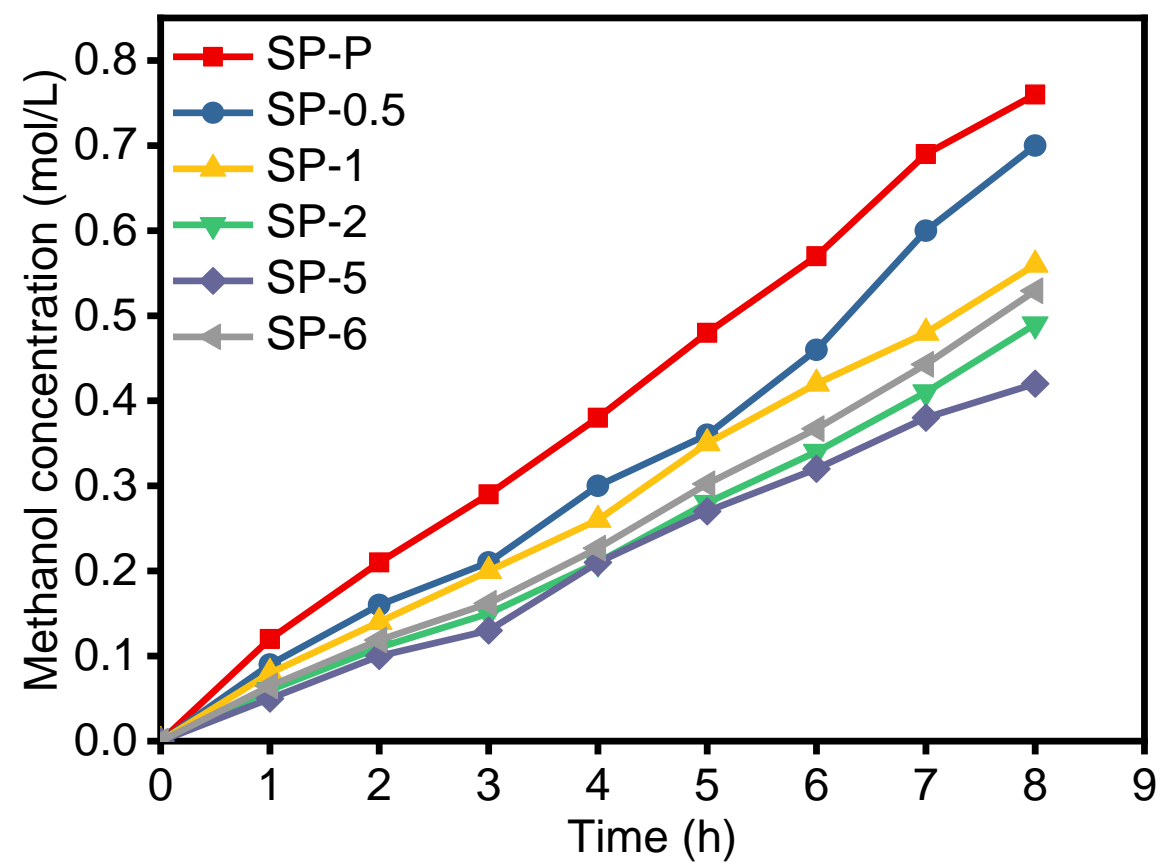

Fig. S8 Methanol concentration profile of diffusate compartment with time for synthesized membranes 